\title{
Vandalisme Koleksi di Unit Pelayanan Teknis (UPT) Perpustakaan Universitas Bengkulu
}

\author{
Isran Elnadi \\ Pustakawan Perpustakaan Universitas Bengkulu \\ e-mail: isranelnadi@gmail.com
}

\begin{abstract}
The effect of vandalism was the loss of the beauty of the book, damaged of paper, the loss of the information of the book thus reducing the comfort of reading. The problems of this study were (1) what is the causes of vandalism collection, (2) what is the weaknesses of librarian and staff so the occurrence of vandalism collection, (3) what is the solution to avoid of vandalism. The method of this study was descriptive qualitative. The populations of this study were the circulation collection at the second floor from 000 classifications (public in general) to 900 classifications (history and geography) that had vandalism by the librarian. Data collection of this study divided into two aspects, (a) primer data, (b) secondary data). The result of this study was for public in general (000) there was 1.700 copies (31.75) had vandalism with the type of the book crossed out, highlighter, torn, and underline. Philosophy of collection (100) that vandalism was 61 copied (1.65). Religion collection (200) 171 copies indicated vandalism. Social science (300) 68 copies indicated vandalism (0.3). Linguistics (400) 108 copies indicated vandalism (2.74). Pure Science (500) indicated vandalism 68 copies $(0.71 \%)$. Collection of applied sciences $(600)$ indicated vandalism 178 copied $(0.999 \%)$. Art and sport (700) indicated vandalism 7 copies $(0.379)$. Literature (800) indicated vandalism 141 copies (3.484\%). History and Geography (900) indicated vandalism 141 copies $(3.484 \%)$. The causes of vandalism collection, such as: Peer influence, parents often gives bad example to their children like throwing the trash out of place. Mass Media, the attitude of not taking care of the community to the act vandalism, lack of supervision of staff or librarians against the user/visitor.
\end{abstract}

Key Words: Vandalism, Academic Library, Library of University of Bengkulu

\begin{abstract}
Abstrak
Vandalisme mengakibatkan hilangnya keindahan buku, rusaknya kertas, hilangnya informasi sehingga akan mengurangi kenyamanan membaca. Adapun rumusan masalah Penelitian ini yaitu : (1) apa yang menyebabkan
\end{abstract}

Tik Ilmeu : Jurnal Ilmu Perpustakaan dan Informasi

Perpustakaan STAIN Curup | p-issn: 1496125591; e-issn:1496125960 
terjadinya vandalisme koleksi, (2) apa kelemahan pustakawan dan staf sehingga terjadinya vandalisme koleksi, (3) apa solusinya agar koleksi terhindar dari tindakan vandalisme. Tujuan penelitian ini yaitu (1) untuk mengetahui kenapa terjadinya vandalisme koleksi, (2) untuk mengetahui kelemahan pustakawan dan staf sehingga terjadinya vandalisme koleksi, (3) untuk mengetahui apa solusinya agar koleksi terhindar dari tindakan vandalisme. Metode penelitian ini adalah Deskriptif kualitatif. Populasi penelitian koleksi sirkulasi yang berada di lantai dua dari klasifikasi 000 (karya umum) sampai klasifikasi 900 (sejarah dan geografi), yang tervandalisme oleh pemustaka. Pengumpulan data penelitian ini dibagi dua, (a) data primer, (b) Data sekunder, Hasil dari penelitian adalah : Untuk karya umum (000) terdapat 1.700 ekpl $(31,75)$ tervandalisme dengan tipe buku dicoret, distabilo, dirobek dan digaris bawahi. koleksi Ilmu Filsafat (100) jumlah tervandalisme $61 \mathrm{ekpl}(1,65 \%)$. Koleksi ilmu agama (200) jumlah tervandalisme $171 \mathrm{ekpl}(3,84 \%)$. Ilmu sosial (300) tervandalisme $68 \mathrm{ekpl}$ $(0,31 \%)$. Ilmu bahasa (400) tervandalisme 108 ekpl (2,74\%). Ilmu murni (500) tervandalisme $68 \mathrm{ekpl}(0,71 \%)$. Koleksi ilmu terapan (600) tervandalisme $178 \mathrm{ekpl}(0,999 \%)$. Kesenian dan olahraga (700) tervandalisme $7 \mathrm{ekpl}(0,379 \%)$. Ilmu sastra (800) tervandalisme $141 \mathrm{ekpl}$ $(3,484 \%)$. Ilmu sejarah dan geografi (900) tervandalisme 141 ekpl $(3,484)$. Penyebab tindakan vandalisme koleksi antara lain : Pengaruh rekan sebaya, orang tua sering memberikan contoh yang kurang baik kepada anak sepert membuang sampah tidak pada tempatnya, media masa, sikap tidak ambil peduli masyarakat kepada tindakan vandalisme, kurangnya pengawasan staf atau pustakawan terhadap pemustaka.

Kata Kunci : Vandalisme, Perpustakaan Perguruan Tinggi, Perpustakan Universitas Bengkulu

\section{A. PENDAHULUAN}

Perpustakaan adalah sebuah wadah atau tempat yang disediakan oleh perguruan tinggi sebagai sarana untuk menunjang proses pendidikan. Kehadiran perpustakaan di harapkan dapat membantu dan mempermudah pemustaka dalam menyelesaikan proses pendidikannya. untuk tercapainya tujuan pemustaka dalam menyelesaikan proses pendidikannya, perpustakaan memiliki banyak koleksi, seperti buku tek, majalah, karya ilmiah, laporan penelitian dan sebagainnya.

Banyaknya koleksi di perpustakaan menimbulkan masalah lain, yakni penyalahgunaan koleksi yang dilakukan oleh pemustaka. Penyalahgunaan koleksi tersebut dapat berupa dicoret-coretnya buku tek, merobek, membakar 
bahkan membasahi buku bacaan. Kegiatan yang mengakibatkan hilangnya keindahan buku bacaan, rusaknya kertas, hilangnya informasi yang ada dalam buku bacaan sehingga mengakibatkan ketidaknyamanan pemustaka dalam membaca merupakan istilah dari vandalisme.

Menurut Perez (2009), ada beberapa tipe penyalahgunaan koleksi diantaranya vandalisme eksterior seperti mencoret dinding dan merusak jendela. Vandalisme interior, yakni vandalisme yang dilakukan di dalam bangunan perpustakaan. Seperti merobek bahan bacaan dan merusak kertas.

Berdasarkan uraian tersebut, saya ingin mengkaji mengenai penyalahgunaan koleksi (vandalisme) yang terjadi di UPT Perpustakaan Universtias Bengkulu, karena perpustakaan tersebut merupakan salah perpustakaan perguruan tinggi yang bagus di Bengkulu.

Vandalisme mengakibatkan hilangnya keindahan buku, rusaknya kertas, hilangnya informasi sehingga akan mengurangi kenyamanan membaca. UPT Perpustakaan Universitas Bengkulu sebagai salah satu perpustakaan perguruan tinggi yang baik di Bengkulu, menarik perhatian saya untuk dijadikan sebagai tempat pengkajian, karena berdasarkan pengamatan banyak pemustaka pernah melakukan vandalisme buku-buku perpustakaan. Begitu juga buku-buku koleksinya yang rusak oleh vandalisme (Constantia. 1995).

Vandalisme merupakan kerusakan atau penyalahgunaan koleksi perpustakaan yang disebabkan oleh perbuatan manusia. Di dalam Kamus Besar Bahasa Indonesia (2003, 1116), istilah vandalisme diartikan sebagai "perbuatan merusak dan menghancurkan hasil karya seni dan barang berharga lainnya (keindahan alam dsb)." Penyalahgunaan koleksi seperti memberi tanda tertentu, mencoret-coret yang tidak berarti, penyobekan dan pencurian dapat dimasukkan dalam perilaku vandalisme.

Dalam mengkaji vandalisme koleksi buku perpustakaan Universitas Bengkulu, penulis mengacu pada teori-teori vandalisme, yaitu Enjoyment Theory, Equity Control Theory, dan Aesthetic Theory. (Goldstein, 1996). Enjoyment theory menjelaskan bahwa seseorang melakukan vandalisme karena adanya tekanan psikologis dari luar yang mengakibatkan ketidak seimbangan, misalnya sukses akademik belum tentu sukses di masyarakat. Tekanan psikologis juga dapat berupa kurangnya rasa humor di kampus.

Berdasarkan uraian tersebut, saya ingin mengkaji mengenai penyalahgunaan koleksi (vandalisme) yang terjadi di UPT Perpustakaan Universtias Bengkulu, karena perpustakaan tersebut merupakan salah perpustakaan perguruan tinggi yang bagus di Bengkulu. 


\section{Rumusan Masalah}

1. Apa yang menyebabkan terjadinya vandalime koleksi di UPT Perpustakaan Universitas Bengkulu?

2. Apa kelemahan pustakawan dan staf sehingga terjadinya vandalisme koleksi UPT Perpustakaan Universitas Bengkulu

3. Apa solusinya agar koleksi di UPT Perpustakaan Universitas Bengkulu terhindar dari tindakan vandalisme pemustaka.

\section{Tujuan Penelitian}

1. Untuk mengetahui apa yang menyebabkan terjadinya vandalisme koleksi di UPT Perpustakaan Universitas Bengkulu.

2. Untuk mengetahui kelemahan pustakawan dan staf sehingga terjadinya vandalisme di UPT Perpustakaan Universitas Bengkulu.

3. Mencari solusi agar koleksi di UPT Perpustakaan Universitas Bengkulu terhindar dari tindakan vandalisme pemustaka.

\section{Manfaat Penelitian}

1. Sebagai bahan dalam penyusunan program kerja UPT Perpustakaan agar tindakan vandalisme koleksi dapat dicegah.

2. Dengan hasil penelitian ini dapat memberikan perubahan kepada pustakawan dan staf, supaya bisa memanimalisir tindakan vandalisme koleksi di UPT Perpustakaan Universiitas Bengkulu.

3. Dapat memberikan perubahan dalam mengembangkan kemampuan profesionalisme mencari solusi agar pemustaka tidak melakukan vandalisme koleksi di UPT Perpustakaan Universitas Bengkulu.

\section{Metode Penelitian}

Penelitian ini menggunakan metode deskriptif kualitatif, analisis vandalisme koleksi.

\section{Populasi penelitian}

Populasi penelitian adalah koleksi sirkulasi yang berada di lantai dua dari klasifikasi 000 (karya umum) sampai klasifikasi 900 (sejarah dan geografi), yang tervandalisme oleh pemustaka. Pengumpulan data dalam penelitian ini dibagi dua, (a) data primer, (b) Data sekunder.

\section{Kajian Pustaka}

Vandalisme adalah perusakan terhadap milik umum. Kamus besar Bahasa Indonesia mendefinisikan vandalisme sebagai berikut : "Vandalisme 
adalah perbuatan merusak dan menghancurkan hasil karya seni dan barangbarang berharga lainnya (kerusakan alam, dsb) atau perusakan dan penghancuran secara kasar dan ganas". (KBBI, 1995).

Sedangkan Merriam - Webster dalam Webster's Ninth New Collegiate Dictionary mendefinisikan: "Vandalisme is hostility to, or willful destruction or defacement of, thing of beauty, as work art, literature, historical monument, etc. (The Psychology of Vandalisme, 1996)

English-Indonesia Dictionary mengatakan : Vandalisme adalah perusakan dan penghancuran barang-barang seni serta barang-barang berharga lainnya dengan sengaja yang sasarannya biasanya barang-barang milik umum". (English-Indonesia Dictionary, 1990).

\section{Jenis-jenis Vandalisme}

Jenis-jenis vandalisme dapat dikelompokkan sebagai berikut : (1) Acquisitive vandalism (2) Tactical vandalism, (3) Ideological vandalism, (4) Vindictive vandalism, (5) Play vandalism, (6) Malicious vandalism, (Cohen, 1996:34).

Sedangkan Zeisel membagi vandalisme menjadi empat macam, yaitu :

1. Malicous vandalism, as describe above by Cohen.

2. Misnamed vandalism, that is, damage due more ti poor design planning than destructive intent, for exemple, a basketball placed too close to the windows of school hallway.

3. Nonmalicous property damage, for exemple, youth painting lines on a wall or elsewhere to define a goal or playing boundaries.

4. Hidden maintenance damage, that is, gradual property defacemant as a result of poor planning of location, materials, or design.

Rahayuningsih (2007: 2) mengatakan vandalisme dirasakan lebih banyak menghadirkan kerugian daripada keuntungannya. Akibat tindakan vandalisme, koleksi perpustakaan menjadi berkurang sehingga dibutuhkan biaya yang tidak sedikit untuk memulihkan kembali kelengkapan koleksi perpustakaan.

Hal ini sesuai dengan pernyataan (Soeatminah, 1992) yaitu: "Manusia yang tidak bertanggungjawab merupakan perusak yang paling hebat, karena tidak hanya menyebabkan kerusakan tetapi juga hilangnya bahan pustaka."Pemustaka" perpustakaan dapat bertindak sebagai lawan atau juga kawan dalam usaha pelestarian bahan pustaka. Sulistyo-Basuki menegaskan bahwa: "Manusia dalam hal ini pemakai perpustakaan dapat 
merupakan lawan atau juga kawan”. Pemakai perpustakaan menjadi kawan bilamana dia membantu pengamanan buku dengan cara menggunakan bahan pustaka secara cermat dan hati-hati.

\section{Penyalahgunaan Koleksi}

Pelaku tindakan vandalisme di perpustakaan, mengarah kepada pemustaka perpustakaan itu sendiri. Kemungkinan pemustaka perpustakaan sebagai pelaku vandalisme dikarenakan pemustaka belum memahami arti keberadaan sebuah perpustakaan, termasuk juga keberadaan koleksinya. Selain pemustaka perpustakaan, tidak menutup kemungkinan staf dan pustakawan itu sendiri sebagai pelaku vandalisme, karena mengakibatkan kerusakan koleksi perpustakaan. Hal ini juga sejalan dengan pendapat Dureau dan Clement $(1990,20)$ kerusakan bahan pustaka disebabkan oleh faktor manusia, bisa dilakukan oleh staf dan pustakawan perpustakaan maupun pemustaka itu sendiri.

\section{Kerugian Tindakan Vandalisme Koleksi Bahan Pustaka}

Vandalisme koleksi dapat mengakibatkan kerugian yang sangat besar bagi perpustakaan. Kerugian ini dibagi dua yaitu kerugian secara finansial dan kerugian secara sosial. Kerugian secara finansial yaitu kerugian yang dirasakan oleh perpustakaan dalam hal dana yang harus dikeluarkan untuk mengganti koleksi yang rusak, memperbaiki kerugian kertas dan menjaga kualitas bahan pustaka. The UCSD Libraries menyatakan, telah memperbaiki lebih dari seribu halaman setiap bulan, dan kebanyakan dirusak secara sengaja atau sebagai akibat dari tindakan perusakan, mutilasi. (http://Orpheus.ucsd.edu/preservation/mutilate.html, 2000).

Bahkan peringatan yang tegas dinyatakan dalam artikel yang berjudul Vandalism of Library Books tentang besarnya biaya yang dikeluarkan untuk memperbaiki koleksi yang rusak. Peringatan itu berbunyi : "Please be aware that a mutilated book or journal may cost anywhere from a few dollars to hundreds replace." (http//library.sag.edu/webref/what_new/newmain.htm\#wnw999,200 0 ). Kerugian sosial yang dialami oleh perpustakaan karena adanya koleksi yang rusak antara lain adalah berkurangnya kepercayaan atau dapat memberikan suatu citra (image) yang kurang baik terhadap perpustakaan sebagai sumber informasi. Misalnya tindakan mutilasi dapat menimbulkan, rasa marah dan frustasi pemustaka yang menginginkan suatu artikel di suatu majalah yang ternyata tidak ada karena telah dirobek orang lain.

Hal ini sesuai dengan sebuah pernyataan dalam artikel yang berjudul Vandalism of Library Books : "More frustrating still is actually finding the 
right volume, turning to the page where the article "should be", and discovering that someone has torn or cut out the pages." (Sumber:http:// library.sage.edu/webref /what_new/newmain.htm\#wnw99g, 2000). Pemustaka terkadang harus menunggu beberapa hari untuk memperoleh artikel yang diinginkan, karena harus menunggu perbaikan majalah oleh pustakawan. Hal ini sesuai dengan pendapat Constantinou (1995) yaitu: "Students cannot use the library's resources to their fullest because they cannot find articles in mutilated journals. They often have to wait for days to get replacement pages through ILL services."Bahaya tindakan penyalahgunaan koleksi sangat berbahaya, karena akan berdampak buruk bagi perpustakaan, antara lain: (a) Terhalangnya transfer informasi dan ilmu pengetahuan serta kemajuannya. (b) Terganggunya iklim pendidikan. (c) Biaya preservasi bahan pustaka yang meningkat. (d) Mengurangi bahkan menghilangkan keindahan koleksi. (e) Berdampak sosial pada lingkungan dan diri objek misalnya menularnya kebiasaan melakukan tindakan penyalahgunaan koleksi kepada orang lain, dan lain sebagainya.

\section{Faktor-faktor yang Mempengaruhi Vandalisme}

\section{(1) Pengaruh rekan sebaya}

Rekan sebaya merupakan faktor utama berlakunya vandalisme. Golongan remaja biasanya lebih mudah terpengaruh dengan rakan sebaya. Rakan sebaya merupakan komponen penting dalam membentuk keperibadian seseorang. Pengaruh rakan sebaya akan mencorakkan sikap, nilai dan tingkah laku seseorang remaja tersebut, terutamanya remaja yang tercicir dan menghadapi masalah dalam institusi keluarga mereka. Kebiasaannya, golongan remaja yang melakukan vandalisme ini merupakan remaja dalam kumpulan. Kumpulan ini tidak mempunyai tujuan dan terjebak dalam budaya yang kurang. Apabila mereka berkumpul timbullah pelbagai idea yang tidak baik termasuklah menconteng harta benda milik orang lain.

\section{(2) Ibu Bapak (orang tua)}

Ibu Bapa atau orang tua adalah pendorong kepada sifat vandalisme di kalangan remaja. Contohnya, ketika ibu bapak membuang sampah atau kulit buah-buahan seperti rambutan dan limau, di samping tidak menghiraukan papan tanda larangan. anak remaja yang terjebak dalam gejala vandalisme berasal daripada keluarga bermasalah atau keluarga yang mengamalkan budaya hidup negatif. Selain itu, kurangnya kawalan dan bimbingan yang sempurna dari pada ibu bapak juga merupakan faktor utama mendorong remaja terjebak dalam gejala negatif ini. 


\section{(3) Media masa}

Media masa mempunyai pengaruh dan kesan yang amat kuat, dan sukar sekali dielakkan dewasa ini. Paparan adegan-adegan negatif dari filemfilem atau rancangan dari barat, yang mempunyai unsur-unsur perlakuan ke arah vandalisme, boleh mempengaruhi remaja melakukan vandalisme. Golongan remaja lazimnya mudah meniru dan mengikut hal yang dilihat di sekeliling termasuk media massa, apalai lagi tanpa bimbingan dan petunjuk sewajarnya.

\section{(4) Sikap tidak ambil peduli masyarakat}

Sikap yang tidak ambil peduli masyarakat juga merupakan faktor berlakunya gejala vandalisme. Remaja adalah produk sistem sebuah masyarakat. Masyarakat yang pincang akhirnya akan melahirkan produk yang pincang. Sikap sesetengah masyarakat kini yang mementingkan soal kebendaan, dan tidak ambil peduli terhadap isu-isu sosial memang merumitkan masalah. Vandalisme biasanya banyak berlaku di bandara, di dinding-dinding kantor, sekolah, kampus dan koleksi perpustakaan. Golongan remaja menconteng dan merusakkan harta benda awam bukannya tidak terpelajar, tetapi generasi yang dilahirkan di bandar sukar dikawal. Di kawasan bandar setengah penduduknya tidak ambil peduli terhadap apa yang berlaku di sekeliling mereka. Oleh karena itu golongan remaja merasakan diri mereka bebas, untuk meneruskan gejala negatif ini tanpa menghiraukan rasa tanggungjawab, terhadap harta benda termasuk koleksi bahan pustaka. (S.M Mohamed Idris, 2008).

\section{(5) Kurangnya pengawasan Staf dan Pustakawan}

Kurangnya pengawasan staf dan pustakawan terhadap koleksi di perpustakaan, juga memberikan peluang bagi pemustaka untuk melakukan vandalisme koleksi yang ada di ruang perpustakaan. Untuk pengawasan ini, pertama pustakawan sering mengontrol pemustaka yang sedang mencari koleksi di rak atau sedang membaca, kedua pihak perpustakaan memasang CCTV, agar setiap kejadian di ruang koleksi dan ruang baca bisa dilihat (diawasi) oleh CCTV ini.

\section{B. HASIL DAN PEMBAHASAN}

\section{Jumlah Koleksi}

Jumlah koleksi UPT Perpustakaan Universitas Bengkulu dari karya umum (000) sampai klasifiksi (900), untuk karya umum berjumlah 5.355 eksemplar, klasifikasi (100) filsafat 3.693 eksemplar, klasifikasi (200) agama 
4.455 eksemplar, klasifikasi (300) ilmu sosial 22.148 eksemplar, klasifikasi (400) bahasa 3.948 eksemplar, klasifikasi (500) ilmu murni 8.901 esemplar, klasifikasi (600) ilmu terapan 17.812 esemplar, klasifikasi (700) kesenian dan olahraga 1.849 eksemplar, klasifikasi (800) sastra 4.047 eksemplar dan klasifikasi (900) sejarah dan geografi. Sumber data : Laporan Bagian Pengolahan Koleksi Juni 2017.

Untuk mengalisa data koleksi sirkulasi UPT Perpustakaan Universitas Bengkulu yang tervandalisme, peneliti membagi empat tipe vandalisme yaitu

1. Dicoret

2. Distabilo

3. Dirobek

4. Digaris bawahi.

Agar memudahkan peneliti dalam menganalisa data koleksi sirkulasi UPT Perpustakaan Universitas Bengkulu yang tervandalisme, peneliti mencari koleksi di rak koleksi dan memisahkan koleksi berdasarkan klasifikasi yang tervandalisme. Setelah itu menghitung berdasarkan banyaknya eksemplar. Sehingga dalam menganalisa data peneliti bisa terfokus untuk mempersentasekan berapa koleksi yang tervandalisme oleh pemustaka.

Untuk lebih jelasnya, berapa banyak koleksi UPT Perpustakaan Universitas Bengkulu yang tervandalisme oleh pemustaka bisa lihat pada tabel berikut :

Tabel 1. Koleksi Karya Umum (000) Yang Tervandalisme

\begin{tabular}{clcc}
\hline N0 & Tipe Vandalisme & Jumlah & $\%$ \\
\hline 1 & Dicoret & 618 & 11,54 \\
2 & Distabilo & 340 & 6,35 \\
3 & Dirobek & 14 & 0,26 \\
4 & Digaris bawahi & 728 & 13,59 \\
& Jumlah tervandalisme & 1.700 & 31,75 \\
$*$ & Yang tidak tervandalisme & 3.655 & 68,25 \\
\hline & Total & 5.355 & 100 \\
\hline
\end{tabular}

Jumlah koleksi Karya Umum (000) yang ada di sirkulasi UPT Perpustakaan Universitas Bengkulu 5.355 eksemplar, setelah dicari terdapat 1.700 eksemplar yang tervandalisme. 
50|Isran Elnadi: Vandalisme Koleksi di Unit...

Tabel 2. Koleksi ilmu filsafat (100) Yang Tervandalisme

\begin{tabular}{|c|c|c|c|}
\hline N0 & Tipe Vandalisme & Jumlah & $\%$ \\
\hline 1 & Dicoret & 19 & 0,51 \\
\hline 2 & Distabilo & 14 & 0,38 \\
\hline 3 & Dirobek & 7 & 0,19 \\
\hline \multirow[t]{2}{*}{4} & Digaris bawahi & 21 & 0,57 \\
\hline & Jumlah tervandalisme & 61 & 1,65 \\
\hline \multirow[t]{2}{*}{ * } & Yang tidak tervandalisme & 3.632 & 98,35 \\
\hline & Total & 3,693 & 100 \\
\hline \multicolumn{4}{|c|}{$\begin{array}{l}\text { Dari jumlah koleksi ilmu filsafat }=\mathbf{3 . 6 9 3} \text { eksemplar yang ada d } \\
\text { sirkulasi UPT Perpustakaan Universitas Bengkulu, ada } 61 \text { eksempla } \\
\text { tervandalisme oleh pemustaka. }\end{array}$} \\
\hline N0 & Tipe Vandalisme & Jumlah & $\%$ \\
\hline 1 & Dicoret & 14 & 0,31 \\
\hline 2 & Distabilo & 17 & 0,38 \\
\hline 3 & Dirobek & 28 & 0,63 \\
\hline \multirow[t]{2}{*}{4} & Digaris bawahi & 112 & 2,51 \\
\hline & Jumlah tervandalisme & 171 & 3,84 \\
\hline \multirow[t]{2}{*}{ * } & Yang tidak tervandalisme & 4.284 & 96,16 \\
\hline & Total & 4.455 & 100 \\
\hline
\end{tabular}

Tabel 3. Koleksi ilmu agama (200) Yang Tervandalisme

Jumlah koleksi ilmu agama (golongan 200) yang ada di sirkulasi UPT Perpustakaan Universitas Bengkulu berjumlah $=4,455$ eksemplar, dari 4.455 eksemplar terdapat 171 eksemplar koleksi yang tervandalisme.

Tabel 4. Koleksi ilmu Sosial (300) Yang Tervandalisme

\begin{tabular}{clcc}
\hline N0 & \multicolumn{1}{c}{ Tipe } & Jumlah & $\%$ \\
\hline 1 & Dicoret & 10 & 0,05 \\
2 & Distabilo & 4 & 0,02 \\
3 & Dirobek & 2 & 0,01 \\
4 & Digaris bawahi & 52 & 0,23 \\
& Jumlah tervandalisme & 68 & 0,31 \\
$*$ & Yang tidak tervandalisme & 22.080 & 99,69 \\
\hline & Total & 22.148 & 100 \\
\hline
\end{tabular}

Jumlah koleksi Ilmu Sosial (300) 22,148 eksemplar, dari jumlah 22,148 eksemplar, yang tervandalisme oleh pemustaka berjumlah 68 eksemplar. 
Tabel 5. Koleksi ilmu bahasa (400) Yang Tervandalisme

\begin{tabular}{clcc}
\hline N0 & \multicolumn{1}{c}{ Tipe Vandalisme } & Jumlah & $\%$ \\
\hline 1 & Dicoret & 15 & 0,38 \\
2 & Distabilo & 14 & 0,35 \\
3 & Dirobek & 4 & 0,10 \\
4 & Digaris bawahi & 75 & 1,90 \\
& Jumlah tervandalisme & 108 & 2,74 \\
$*$ & Yang tidak tervandalisme & 3.840 & 97,26 \\
\hline & Total & 3,948 & 100 \\
\hline
\end{tabular}

Koleksi ilmu bahasa yang ada di sirkulasi UPT Perpustakaan Universitas Bengkulu berjumlah $=3,948$ eksemplar, dari jumlah yang terterah di tabel tersebut, ada 108 eksemplar yang tervandalisme.

Tabel 6. koleksi ilmu murni (500) Yang Tervandalisme

\begin{tabular}{clcc}
\hline N0 & \multicolumn{1}{c}{ Tipe Vandalisme } & Jumlah & $\%$ \\
\hline 1 & Dicoret & 25 & 0,28 \\
2 & Distabilo & 0 & 0,00 \\
3 & Dirobek & 13 & 0,15 \\
4 & Digaris bawahi & 25 & 0,28 \\
& Jumlah tervandalisme & 63 & 0,71 \\
$*$ & Yang tidak tervandalisme & 8.838 & 99,29 \\
\hline & Total & 8,901 & 100 \\
\hline
\end{tabular}

Jumlah koleksi ilmu murni di sirkulasi UPT Perpustakaan Universitas Bengkulu berjumlah $=8,901$ eksemplar, dari koleksi 8.901 eksemplar tersebut ada 63 eksemplat yang tervandalisme oleh pemustaka.

Tabel 7. Koleksi ilmu terapan (600) yang tervandalisme

\begin{tabular}{|c|c|c|c|}
\hline N0 & Tipe & Jumlah & $\%$ \\
\hline 1 & Dicoret & 71 & 0,399 \\
\hline 2 & Distabilo & 7 & 0,039 \\
\hline 3 & Dirobek & 32 & 0,180 \\
\hline \multirow[t]{2}{*}{4} & Digaris bawahi & 68 & 0,382 \\
\hline & Jumlah tervandalisme & 178 & 0,999 \\
\hline \multirow[t]{2}{*}{$*$} & Yang tidak tervandalisme & 17.634 & 99,001 \\
\hline & Total & 17.812 & 100 \\
\hline
\end{tabular}


Jumlah koleksi ilmu terapan sirkulasi UPT Perpustakaan Universitas Bengkulu berjmlah $=17,812$ eksemplar, adapun yang tervandalisme berjumlah 178 eksemplar oleh pemustaka.

Tabel 8. Kokeksi kesesnian dan olahraga (700) yang tervandalisme

\begin{tabular}{clcc}
\hline N0 & \multicolumn{1}{c}{ Tipe } & Jumlah & $\%$ \\
\hline 1 & Dicoret & 2 & 0,108 \\
2 & Distabilo & 0 & 0,000 \\
3 & Dirobek & 5 & 0,270 \\
4 & Digaris bawahi & 0 & 0,000 \\
& Jumlah tervandalisme & 7 & 0,379 \\
$*$ & Yang tidak tervandalisme & 1.842 & 99,621 \\
\hline & Total & 1.849 & 100 \\
\hline
\end{tabular}

Jumlah koleksi ilmu terapan sirkulasi UPT Perpustakaan Universitas Bengkulu berjmlah $=1,849$ eksemplar, adapun yang tervandalisme berjumlah 7 eksemplar oleh pemustaka.

Tabel 9. Koleksi ilmu sastra (800) Yang Tervandalisme

\begin{tabular}{clcc}
\hline N0 & \multicolumn{1}{c}{ Tipe } & Jumlah & $\%$ \\
\hline 1 & Dicoret & 40 & 0,988 \\
2 & Distabilo & 33 & 0,815 \\
3 & Dirobek & 44 & 1,087 \\
4 & Digaris bawahi & 24 & 0,593 \\
& Jumlah tervandalisme & 141 & 3,484 \\
$*$ & Yang tidak tervandalisme & 3.906 & 96,516 \\
\hline & Total & 4.047 & \\
\hline
\end{tabular}

Koleksi ilmu sastra di sirkulasi UPT Perpustakaan Universitas Bengkulu berjumlah $=4,047$ eksemplar, adapun yang tervandalisme oleh pemustaka berjumlah 141 eksemplar.

Tabel 10. Koleksi geografi dan sejarah (900) Yang Tervandalisme

\begin{tabular}{clcc}
\hline N0 & \multicolumn{1}{c}{ Tipe } & Jumlah & $\%$ \\
\hline 1 & Dicoret & 8 & 0,415 \\
2 & Distabilo & 3 & 0,156 \\
3 & Dirobek & 3 & 0,156 \\
4 & Digaris bawahi & 7 & 0,363 \\
& Jumlah & 21 & 1,089 \\
$*$ & Yang tidak tervandalisme & 1.908 & 98,911 \\
\hline & Total & 1,929 & 100 \\
\hline
\end{tabular}


Untuk koleksi ilmu geografi dan sejarah di sirkulasi UPT Perpustakaan Universitas Bengkulu berjumlah $=21$ eksemplar yang tervandalisme oleh pemustaka.

\section{KESIMPULAN}

Dari hasil pencarian koleksi di rak koleksi sirkulasi UPT Perpustakaan Universitas Bengkulu, koleksi yang tervandalisme oleh pemustaka, untuk koleksi karya umum (000) terdapat 1.700 ekpl $(31,75)$ tervandalisme dengan tipe buku dicoret, distabilo, dirobek dan digaris bawahi. Sedangkan koleksi Ilmu Filsafat (100) jumlah tervandalisme 61 ekpl $(1,65 \%)$. Koleksi ilmu agama (200) jumlah tervandalisme 171 ekpl $(3,84 \%)$. Koleksi ilmu sosial (300) jumlah tervandalisme 68 ekpl (0,31\%). Untuk koleksi ilmu bahasa (400) tervandalisme 108 ekpl (2,74\%). Koleksi ilmu murni (500) tervandalisme $68 \mathrm{ekpl}(0,71 \%)$. Koleksi ilmu terapan (600) tervandalisme 178 ekpl (0,999\%). Kesenian dan olahraga (700) jumlah tervandalisme $7 \mathrm{ekpl}(0,379 \%)$. Koleksi ilmu sastra (800) tervandalisme 141 ekpl $(3,484 \%)$. Untuk koleksi sejarah dan geografi (900) tervandalisme 141 ekpl $(3,484)$ dengan tipe buku dicoret, distabilo, dirobek dan digaris bawahi. Adapun penyebab tindakan vandalisme koleksi antara lain : Pengaruh rekan sebaya, orang tua sering memberikan contoh yang kurang baik kepada anak (seperti) membuang sampah disembarang tempat, media masa, sikap tidak ambil peduli masyarakat kepada tindakan vandalisme, dan kurangnya pengawasan staf atau pustakawan terhadap pemustaka.

Staf dan pustakawan UPT Perpustakaan UNIB, memberikan bimbingan pemustaka secara kontinyu kepada pemustaka perpustakaan, dengan materi bagaimana pemustaka menjaga dan memelihara fasilitas yang baik. (2) Memasang CCTV di ruang koleksi agar terdetiksi pemustaka yang melakukan kecurangan, (3) membantu pemustaka yang kesulitan dalam menelusur informasi di rak sesuai kebutuhan.

\section{DAFTAR RUJUKAN}

Constantinou, Constantia. 1995. Destruction of Knowledge: A Study of Journal Mutilation at a Large University Library. College and Research Libraries. 56 (6) November (p.497-507).

-----. (2010). The Art of Library: Ikatan Esai Bergizi tentang Seni Mengelola Perpustakaan. Semarang: Badan Penerbit UNDIP.

Dureau, J.M \& Clements, D.W.G. (1990). Dasar- dasar Pelestarian dan Pengawetan Bahan Pustaka. Jakarta: Perpustakaan Nasional R.I. 


\section{4 | Isran Elnadi: Vandalisme Koleksi di Unit. .}

Pérez, Carmen; Cuadrado, Manuel; and Cervera, Amparo. 2009. Understanding University Library Users' Mistreatment of Books. The Journal of Academic Librarianship, 35(2), 177-183

Pusat Pembinaan dan Pengembangan Bahasa Departemen Pendidikan dan Kebudayaan. (1995). Kamus Besar Bahasa Indonesia. Ed.2. Jakarta: Balai Pustaka.

Library Abuse in Academic Institutions : A Comparative Study. Intl. Inform. \& Libr. Rev. 24 (p.291-305). Saleh, A.R. 1995.

Manajemen Perpustakaan perguruan Tinggi. Jakarta : Universitas Terbuka.

Marcel C. Obiagwu (1992). Library Abuse in Academic Institutions, international nformation \& Library Review, 24:4, 291-305, OI:10.1080/10572317. 1992.10762301.

Mutilation of Library Materials. 2000. Tersedia di: http:// Orpheus.ucsd.edu/preservation/mutilate.html. Diakses 11/11/00, pukul 15.15 WIB. Obiagwu, Marcel C. 1992.

Posted by svproject-vandalisme.blogspot.com at 2:37 AM No comments: Email ThisBlogThis!Share to TwitterShare to FacebookShare to Pinterest Home.

Rahayuningsih, F. (2007).Vandalisme Di erpustakaan. Genta Pustaka: Menuju Perspektif Baru Perpustakaan Vol. I Nomor 4. Semarang: Perpustakaan Unika Soegijapranata.

S.M Mohamed Idris. 2008. Kita masih bergelut dengan vandalisme, utusan maslaysia, 24 April.

Soeatminah. 1992. Perpustakaan Kepustakawanan dan Pustakawan. Yogyakarta: Kanisius.

Sulistyo-Basuki. 1991. Pengantar Ilmu Perpustakaan. Jakarta: Gramedia Pustaka Utama.

Teknik dan Jasa Dokumentasi . Jakarta : Gramedia Pustaka Utama. Vandalism of Library Books. 2000.

Vandalisme kian meruncing, Utusan Malaysia, 13 Julai 2010 